\title{
THE SCRIBE'S COLUMN
}

\section{'Diagnostic Formulation'}

There have been some complaints that the term 'diagnostic formulation' has caused difficulties to examiners and candidates for the MRCPsych Examination, and APIT have recently written an open letter to the chief examiner about this (Bulletin, April, p. 67). This has caused me to think about the problem, and to jot down a few thoughts (most of which I may say I have stolen from other people). Initially examination candidates were expected to submit a formulation in writing, but this is no longer the case. Examiners, however, still expect a brief diagnostic formulation. I have therefore summarized four accounts of 'formulation'.

A. The Oxford English Dictionary gives the definition of 'formulation' as: 'to reduce to, to express in a formula; to set forth in a definite and systematic statement'. The definition of 'formula' is given as a 'set form of words in which something is defined, stated or declared'.

B. The Department of Psychiatry Teaching Committee (Institute of Psychiatry) in their notes on eliciting and recording clinical information, refer to an 'initial formulation' as: 'a doctor's assessment of the case rather than a re-statement of the facts. Its length, layout and emphasis will vary considerably from one patient to another. It should always include a discussion of the diagnosis, the aetiological factors which seem important, as well as taking into account the patient's life situation and background, with a plan of treatment and an estimate of prognosis. Regardless of the uncertainty or complexity of the case, a provisional diagnosis should always be specified'.

C. Curran and Guttmann (Psychological Medicine, 2nd Edition) stated 'Psychiatric diagnosis (or classification) is not exhausted by describing a clinical picture in terms of a syndrome or reaction type. When attempting to make a more complete psychiatric diagnosis the following should be distinguished:

(1) the descriptive aspect, which consists of the syndrome or reaction type that is observed.

(2) the aetiological aspect, which comprises the assessment of the physical, psychological and constitutional factors, and their relative importance in bringing about the reaction in question.

(3) the previous personality, since no reaction can be fully understood without taking into account the reacting personality, as seen in the light of the past history and environment.
(4) the prognosis, as the practical value of any diagnosis lies in its prognostic implications.

D. An APIT workshop on examination techniques stated that a 'diagnostic formulation' was an account of deductions based on data obtained from the history and examination, followed by management plans. They thought that it should include:

(1) A brief 2 or 3 line Introduction stating the problem, e.g. 'This is a 35 year old housewife whose main complaint is that she has been unable to leave her home for the past 2 years'.

(2) The differential diagnosis: e.g. (1) Agoraphobic syndrome, (2) Depressive illness, (3) Other outside possibilities.

(3) Justification: The reasons for this differential diagnosis, including the positive points in the history and examination which make one diagnosis more likely than others.

(4) Further investigations. History from the informant and old notes. Relevant physical and psychological investigations.

(5) Management plans-? admission to hospital/ psychological treatment/Family/Rehabilitation/ Long term treatment, related to prognosis.

\section{Conclusion}

A 'diagnostic formulation' is not a formal diagnosis, though it should include a differential diagnosis, nor is it a life history and mental state of the patient. It is a summary of the relevant genetic, constitutional and personality factors and their interaction with the aetiological factors, taking into account the patient's life situation, together with a provisional diagnosis and plan of treatment. If a psychiatric diagnostic formulation is in effect a shorthand description, the following two examples suggest a framework for what might be presented.

'This nineteen year old single student of good premorbid personality with a family history of affective illness is suffering from a depressive reaction to work and domestic stresses which should respond to medication and supportive psychotherapy.'

'A forty-five year old unmarried University professor with paranoid personality traits and a history of heavy consumption of alcohol who has developed delusional ideas of grandeur, with no evidence of physical disease and an uncertain prognosis.' 
I may have got this all wrong from beginning to end, but that is a risk for anyone who tries to interfere helpfully. I daresay the Pundits of Edinburgh and the Scholars of Denmark Hill will not only disagree with everything I have written, but with one another as well. I shall follow any future correspondence about this with great interest.

EZRA THE SCRIbE

\title{
PSYCHIATRY OBSERVED-PERSONAL REFLECTIONS IN RETIREMENT
}

\author{
K. S. JONES \\ Retired Consultant Psychiatrist
}

Here I was engaged in a profession in which I did not know
my way about!

C. G. JUNG

Having reached the age at which the option can be exercised in my specialty, I retired, after twenty years as a whole-time consultant psychiatrist, in the summer of 1977.

Junior posts had variably been intriguing and stressful and Jung's words summarize my novitiate. My senior registrarship had, ironically, shown me the value of an active out-patient department backed up by a small number of beds-ironically because in 1957 I was confronted with the overall care of more than 600 beds, all for male patients, and an out-patient department divided between a general hospital and a psychiatric hospital. These two hospitals were geographically only two miles apart but conceptually were widely separated: space does not permit expansion of this theme.

Over the years a major effort in the psychiatric hospital-it would be invidious to select particular groups involved and impossible to pay tribute to them all: nor would I stigmatize those unduly apprehensive of change or blind to the need for it-resulted in reduction of overcrowding, opening of closed wards, wide extension of elementary amenities, and some integration of in-patient and out-patient work. The final development of sectorization was a major advance (in which consistent personal participation was prevented by absence on sick-leave: in this connection I am glad to acknowledge the tolerance of my employing authorities and of my immediate consultant colleague) fostering more intimate rapport among most of us concerned with treatment in the wards. Throughout, physical and social therapeutic advances, including legal reform, were vital instruments for change.

The out-patient clinics eventually became united in the general hospital, and in 1967 my catchment area was halved, from an impossible 130,000 , by the arrival of the colleague mentioned above. There seemed to be an increasing number of referrals from the wards, many inevitably the consequence of self-poisoning, and finding adequate time for assessment and treatment was often challenging. Government advice that all such patients should be psychiatrically examined acquired a hollow note, and the problem was quite often compounded by the impression that referrals sought 'disposal' rather than uncommitted advice, a motivation which was understandable but sometimes unattractive.

A research interest can add an extra zest to routine activities, and committee work is unavoidable in psychiatry because of its influence on the total therapeutic environment. Although it is an unfashionable admission, service on Hospital Management and other Committees had its own satisfactions (and, in passing, involvement in the preparation of an argument for the foundation of a medical school in Swansea was frankly enjoyable).

Multidisciplinary teams have a long history although lacking this dignified title. I support their formal recognition but still believe that the consultant should retain the final responsibility for decisions affecting his or her patients. From a mature matrix of consultants - and this may prove elusive! - a medical administrator should be elected for a fixed term, be given sessional relief and efficient secretarial help, and be expected to encourage the smooth internal and external operation of the hospital. Such an administrator should strive to realize that there is no complete safety in hospital matters and that a search for this will prove stultifying. The heroic, or alternatively sacrificial, rôle of some old-time medical superintendents should be discounted. Finally the tyro in the field of administration might do well to keep in mind the comment of a surgical teacher in my youth that 'even the least experienced is not infallible'. 